\title{
Common mucocutaneous manifestations of patients with End Stage Renal Disease: A comprehensive review study
}

\author{
SEYED-MOHAMAD-SADEGH MIRAHMADI ${ }^{1}, \mathrm{KIMIA} \mathrm{SALEH} \mathrm{ANARAKI}^{2}$, AZADEH GOODARZI ${ }^{*}$ \\ ${ }^{1}$ Department of General Medicine, School of Medicine, Iran University of Medical Sciences (IUMS), Tehran, Iran \\ ${ }^{2}$ Shahid Beheshti University of Medical Sciences, Tehran, Iran \\ ${ }^{3}$ Department of Dermatology, Rasool Akram Medical Complex, Iran University of Medical Sciences (IUMS), Tehran, Iran \\ ${ }^{*}$ Corresponding author, Dr. Azadeh Goodarzi, Associate professor, Department of Dermatology, Rasool Akram Medical Complex, Iran \\ University of Medical Sciences (IUMS), Tehran, Iran. Email: goodarzi.a@iums.ac.ir; azadeh_goodarzi1984@yahoo.com; \\ Address: Niayesh Street, Sattarkhan Avenue, Rasool Akram Medical Complex, Tehran, Iran; ORCID ID: http://orcid.org/0000-0002-1249- \\ 4429
}

\begin{abstract}
One of the notable points in ESRD patients is the multiplicity of skin manifestations which can include a wide range. It can also affect the living standards of patients due to its many types and severity. Careful study, as well as intense follow-up of these manifestations, can help physicians in timely diagnosis and their control or treatment. In this study, we tried to study the common mucocutaneous manifestations that occur in these patients. All references can be searched from PubMed. Sources of this study have been studied for clinical manifestations, pathophysiology, and treatment of skin manifestations in ESRD patients. In this study, xerosis, pruritus, pigmentation disorders, half and half nails, perforating disorder, and skin infections as well as appendageal disorders (hair and nail) in ESRD patients have been studied. These can be associated with other diseases and increase by disease severity. For better results and more help to patients with this disease, it seems that more and more comprehensive studies are needed.
\end{abstract}

Key words: End stage renal disease, ESRD, mucucutaneous, skin, dermatology, xerosis, pigmentation disorders, infection, perforating disorder, half and half nails

\section{INTRODUCTION}

Kidney disease has affected a significant number of populations over the years. One of the most common diseases in this area is CKD.

The number of patients with end-stage renal disease in different communities is also very significant and these patients must undergo dialysis to survive.

On the other hand, the number of patients has increased because the mortality due to the disease has decreased with their proper medical management.

As we know, the kidney is associated with various organs and systems of the body, and kidney dysfunction affects many parts of the body, one of which is the skin. Patients with this disease should undergo dialysis and these manifestations may appear before and after dialysis.

Studies have shown that ESRD patients are involved in a variety of skin manifestations.[1] It is very important that these manifestations that occur in patients are immediately diagnosed by doctors and it is decided as soon as possible about it and how to deal with it so that the desired manifestation is treated or at least controlled so that more patients' lives Do not be affected by these skin manifestations and their effects Early diagnosis and treatment improve patients' quality of life.

\section{METHODS AND MATERIALS}

We searched PubMed data base for the most relevant and well-designed studies for writing this comprehensive review study.

\section{DISCUSSION}

In this study, we tried to discuss the common mucocutaneous manifestations in patients with ESRD, pathogenesis, clinical features as well as their treatment routes. These are summarized in Table 1 . Here we address per detail to the subtopics of this review.

Table 1: Common mucocutaneous manifestations in patients with ESRD

Table 1: Common mucocutaneous manifestations in patients with ESRD
\begin{tabular}{|l|l|l|l|}
\hline Disorder & Presentation & Pathophysiology & Treatment/control \\
\hline Xerosis & Dry and thickened skin & $\begin{array}{l}\text { It is not yet fully understood, but it appears to be due } \\
\text { to glandular atrophy after a decrease in surface } \\
\text { moisture. }\end{array}$ & $\begin{array}{l}\text { Reduce contact with water as well } \\
\text { as keep skin moist }\end{array}$ \\
\hline Pruritus & $\begin{array}{l}\text { Localized or generalized itching of } \\
\text { varying severity }\end{array}$ & Unknown but seems to be related to parathyroid & Gabapentin, capsaicin \\
\hline $\begin{array}{l}\text { Pigmentation } \\
\text { disorder }\end{array}$ & $\begin{array}{l}\text { Discoloration of the skin, which can } \\
\text { range from pale to red, as well as } \\
\text { brown and yellow }\end{array}$ & $\begin{array}{l}\text { Each color is different but has the effects of disease } \\
\text { on platelets or hemoglobin levels and so on }\end{array}$ & $\begin{array}{l}\text { Optimization of dialysis, } \\
\text { erythropoietin and .... }\end{array}$ \\
\hline Half and half nails & $\begin{array}{l}33 \text { to } 50 \% \text { discoloration of the distal } \\
\text { nails }\end{array}$ & unknown & $\begin{array}{l}\text { Elimination of the main cause of the } \\
\text { disease by kidney transplantation }\end{array}$ \\
\hline $\begin{array}{l}\text { Perforating } \\
\text { disorder }\end{array}$ & $\begin{array}{l}\text { Changing the color and shape of the } \\
\text { skin and creating papules and } \\
\text { nodules and ... }\end{array}$ & Loss of skin collagen and elastic fibers & Retinoids and vitamin A and ... \\
\hline $\begin{array}{l}\text { Mucocutaneous } \\
\text { infections }\end{array}$ & $\begin{array}{l}\text { Superficial skin infection that can be } \\
\text { bacterial, fungal or viral }\end{array}$ & $\begin{array}{l}\text { It is related to the medications taken as well as the } \\
\text { level of the immune system and the general condition } \\
\text { of the body after dialysis }\end{array}$ & $\begin{array}{l}\text { Optimizing dialysis and using a } \\
\text { better method }\end{array}$ \\
\hline
\end{tabular}


Xerosis: Xerosis is one of the most common skin manifestations in ESRD patients Xerosis is referred to as dry skin and means a lack of hydro lipids, Hydro lipids are known as natural skin moisturizers[2]Dry skin is especially common in patients undergoing dialysis in the extensor parts of the limbs. This can lead to general itching and discomfort [3]Xerosis is generally thought to be caused by atrophy of the sebaceous glands, dehydration of the skin layers, and impaired keratinocyte differentiation. [4]xerosis can manifest simultaneously with other factors. In many dialysis patients, xerosis and pruritus disorders are seen with a high prevalence. The study also found that xerosis could be linked to anuria[5] The prevalence of xerosis in ESRD patients has been reported significantly in the above studies and is about $63 \%$ to $96 \%$. [5-12]Various ways to control this disorder have been suggested, one of which is to reduce the duration of skin-to-skin contact with water. It has also been suggested to use superficial skin moisturizers in these patients.[13]

Pruritus: One of the most obvious clinical manifestations in patients with ESRD and uremia is pruritus[14]

Dialysis has only a small effect on reducing pruritus, and in many hemodialysis patients, varying degrees of pruritus have been reported. [13] There was no significant relationship between the age of patients with ESRD and pruritus[15] One study found that severe uremic pruritus may be an independent risk factor for death in ESRD patients.[16]

In ESRD patients, the mechanism of pruritus is particularly complex and in various studies, it is considered the result of functional impairment in different systems.[17]

The physiopathology of uremic pruritus is unclear, but it is thought that joint histamine, parathormone, and electrolytes are co-administered. In the case of electrolytes, more emphasis is placed on calcium and magnesium Newer theories have relied on microinflammation and opioid receptor disorders as possible causes of this manifestation in ESRD patients.[18] In one study, pruritus disappeared after total parathyroidectomy[19]

In a separate study, there was a significant difference in the levels of serum nitrogen, phosphorus, creatinine, and parathyroid hormone in patients with pruritus compared to those without the disorder. So perhaps the pathophysiology of pruritus can be attributed to these factors with a good approximation[15] Different parts of the body can become itchy and symptoms can appear and cause secondary scratches, These issues can affect the patient's physical health and mental health[20] Patients undergoing hemodialysis have a higher percentage of pruritus compared to patients undergoing peritoneal dialysis[15, 21] The prevalence of uremic pruritus in ESRD patients is approximately [6, 21]30-90\%

There are various types of treatment for pruritus in patients that are used according to the available facilities, including calcium and phosphorus level correction, phototherapy, acupuncture, but different results have been reported in each of these methods.[22]

Regarding treatment, many physicians recommend PRURITUS uremic stage management, which initially involves optimizing the dialysis procedure, compensating for dehydration, and nutrition.[23]
UVB phototherapy has had a positive effect on the treatment of refractory pruritus in ESRD patients but is not recommended for a long time due to the increased risk of skin malignancy. [24]

In some cases, the anticonvulsant drugs pregabalin and gabapentin are a good choice for UP management.[24] If we accept inflammation as a cause, we can also use Montelukast as a leukotriene receptor antagonist to control this skin manifestation.[24] capsaicin, natural oils have been studied for controlling UP.[25]

Pigmentation disorder: The second most common finding in ESRD patients is color changes that can have different types. This manifestation can include extensive hyperpigmentation, pale skin, sallow yellow, bleeding, and grayish-brown. The percentage of each of these types of colors can be different [26-31]; Studies have reported a higher prevalence of diffuse pigments and skin pallor than other types.

General or partial paleness of the skin can be caused by anemia of chronic diseases, and yellow colors are due to the deposition of fat-soluble pigments such as lipochrome and carotenoids in the epidermis and subcutaneous.[27]

Since pale skin in ESRD patients is caused by chronic anemia, the idea is to solve this problem by injecting erythropoietin and correct the anemia caused by it.[13]

Hyperpigmentation in patients has shown that it can occur more widely in areas directly exposed to sunlight, but if we minimize exposure to sunlight, and also from sunscreen, this manifestation is largely controlled.[13]

In ESRD and dialysis patients, there is another common skin change called ecchymosis, which is caused by a platelet disorder Also vascular fragility and heparin use during hemodialysis. High concentrations of urea in these patients cause platelet aggregation and guanidosuccinic acid accumulation, which reduces platelet activity and causes uremic bleeding.[28, 32]

The recommended way for ecchymosis is to optimize dialysis, which can have a positive effect on this condition.

Infections: ESRD patients develop various infections may addressed in the field of dermatology, including fungal, bacterial, and viral infections, respectively. [30] But their pathophysiology is not yet fully understood. [33] Fungal peritonitis is one of the most important problems in patients undergoing peritoneal dialysis. [34]

\section{Nail involvement}

Half and half nails: Another manifestation seen in ESRD patients is half and half nails or Lindsay nails in which the distal nail changes color and is 50 to $66 \%$ proximal to white nails. [13] The prevalence of this skin manifestation in ESRD patients is about $40 \%[6]$ The pathophysiology, as well as the specific treatment for this manifestation in these patients, have not yet been conclusively identified.

Koilonychias: Another disorder that occurs in patients with ESRD, especially their nails, is koilonychia.[35] Its pathology is described as due to lack of oxygen or atrophy in the connective tissue [35] About $20 \%$ of patients on dialysis show this nail symptom. [36] Of course, this skin symptom can be hereditary and congenital due to iron deficiency anemia. [35] 
Onicholysis: Another manifestation that some ESRD patients present with on dialysis is onycholysis, which means that the nail separates from its bed. Which can be seen on fingernails and toenails Its prevalence has been discussed in various studies, but it seems to be about $25 \%$ of these patients. [35]

The treatment, as well as the pathophysiology of this condition, have not been mentioned in studies of ESRD patients and it seems that more studies can be done in this field

Onychomycosis: Onychomycosis, which means fungal infection of the nails, has also been seen in patients on dialysis and is another skin manifestation of this type of patient.This manifestation has also been seen with a high prevalence in patients who have undergone kidney transplantation. It seems that this high percentage of the prevalence of this symptom in patients is due to immunosuppressive drugs that patients take after kidney transplantation.[6, 37]

The prevalence of this manifestation among the studied patients is about 35\%. Regarding the manifestation of this lesion, the ratio of toenail to toenail in patients is almost equal and there is a significant difference.[38]

Perforating disorders: Another group of skin disorders in ESRD patients is acquired piercing disorders, which include kyrle disease, piercing folliculitis, and reactive piercing collagenosis.

The prevalence of these manifestations in patients undergoing dialysis is about $10 \%$ and the pathophysiology of these disorders is still unknown.

Kyrle disease occurs in about $15 \%$ of ESRD patients. The disease is such that a series of papules appear in patients.[28]

Reactive perforating collagenosis is another type of It is a gene-dependent skin disorder that has an autosomal dominant or recessive inheritance that affects collagen. This disorder has been present since childhood but manifests itself with trauma, folliculitis, or cold weather. Brownish hairs that can be nodular or verrucous. This lesion can be accompanied by pruritus[39]

Perforating folliculitis is another type of skin manifestation in hemodialysis patients in which degenerated follicles are destroyed along with collagen and elastic fibers, which of course can also be independent of collagen and elastic fibers. This disorder is clinically and histologically similar to other perforating disorders that also involve follicle involvement.[40]

Treatment options for perforating disorders vary, including topical or oral retinoids, vitamin $A$, oral antihistamines, topical steroids, intralesional steroid injections, UVB radiation, allopurinol, cryotherapy, and keratolytic, which can be used according to the patient or available cases.

Others: Studies of dialysis patients have reported other cases that affect patients and affect their lives, including SUBUNGUAL HYPERKERATOSIS, brittle, hair loss, and baldness.

However, these cases have not been studied in detail in the texts and it seems that more studies may be needed to examine these cases in detail. Studies of dialysis patients have reported other cases that affect patients and affect their lives, including SUBUNGUAL
HYPERKERATOSIS, brittle, hair loss.[6, 9, 35]. However, these cases have not been studied in detail in the texts and it seems that more studies may be needed to examine these cases in detail.

Muco manifestations are always important and especially important in people with underlying diseases. Recently, many studies have been done in this field.Skin and mucosa could be a site of many presentations of various systemic involvements that should be kept in mind for better diagnosis, management and treatment (41-56)

\section{CONCLUSION}

As mentioned, cutaneous manifestations are so common in ESRD patients that it is possible to find less disease that does not have at least one of these manifestations. Also, the association of these symptoms with other diseases such as diabetes, etc. increases the severity of these manifestations, so the lives of these patients are greatly affected by the suffering caused by these manifestations and reduces their quality of life and life expectancy.

As mentioned, comprehensive research has been done on this type of manifestation, but further progress in the evaluation and timely management of these disorders requires further studies to be able to provide acceptable assistance to patients with skin disorders caused by ESRD and lead them to a normal life.

\section{REFERENCES}

1. Blaha, T., et al., Dermatologic manifestations in end stage renal disease. 2019. 23(1): p. 3-18.

2. Augustin, M., et al., Diagnosis and treatment of xerosis cutis - a position paper. 2019. 17(S7): p. 3-33.

3. Hiremath, S. and E.V. Lerma, CHAPTER 1 - History and physical diagnosis, in Nephrology Secrets (Fourth Edition), E.V. Lerma, M.A. Sparks, and J. M. Topf, Editors. 2019, Elsevier. p. 1-8.

4. Barco, D. and A. Giménez-Arnau, Xerosis: a Dysfunction of the Epidermal Barrier. Actas Dermo-Sifiliográficas (English Edition), 2008. 99(9): p. 671-682.

5. Kouotou, E.A., et al., [Epidemiological and clinical profile of skin damages in black African patients on chronic hemodialysis]. Pan Afr Med J, 2016. 25: p. 142.

6. Anees, M., et al., Factors Affecting Dermatological Manifestations in Patients with End Stage Renal Disease. J Coll Physicians Surg Pak, 2018. 28(2): p. 98-102.

7. Bhat, Z.Y., et al., Bullous Dermatosis in an End-Stage Renal Disease Patient: A Case Report and Literature Review. Case Rep Nephrol, 2016. 2016: p. 6713807.

8. Osipowicz, K., et al., Development of bullous pemphigoid during the haemodialysis of a young man: case report and literature survey. Int Wound J, 2017. 14(1): p. 288-292.

9. Solak, B., et al., Cutaneuos findings in patients with predialysis chronic kidney disease. J Eur Acad Dermatol Venereol, 2016. 30(9): p. 1609-13.

10. Becker, S., et al., Edema, Hyperpigmentation, Induration: 3 Skin Signs Heralding Danger in Patients on Maintenance Hemodialysis. Medicine (Baltimore), 2016. 95(12): p. e3121.

11. Tajbakhsh, R., et al., Mucocutaneous manifestations and nail changes in patients with end-stage renal disease on hemodialysis. Saudi J Kidney Dis Transpl, 2013. 24(1): p. 36-40.

12. Abbasi, S., et al., A new topical treatment of atopic dermatitis in pediatric patients based on Ficus carica L. (Fig): A randomized, placebo-controlled clinical trial. Complement Ther Med, 2017. 35: p. 85-91. 
13. Galperin, T.A., A.J. Cronin, and K.S. Leslie, Cutaneous manifestations of ESRD. Clinical journal of the American Society of Nephrology : CJASN, 2014. 9(1): p. 201-218.

14. Yosipovitch, G., et al., Skin barrier structure and function and their relationship to pruritus in end-stage renal disease. Nephrol Dial Transplant, 2007. 22(11): p. 3268-72.

15. Hu, T., et al., Clinical features and risk factors of pruritus in patients with chronic renal failure. Experimental and therapeutic medicine, 2019. 18(2): p. 964-971.

16. Wu, H.Y., et al., Prognostic importance and determinants of uremic pruritus in patients receiving peritoneal dialysis: $A$ prospective cohort study. PLoS One, 2018. 13(9): p. e0203474.

17. Suseł, J., et al., Uraemic pruritus markedly affects the quality of life and depressive symptoms in haemodialysis patients with end-stage renal disease. Acta Derm Venereol, 2014. 94(3): p. 276-81

18. Attia, E.A. and A.A. Hassan, Uremic pruritus pathogenesis, revisited. Arab J Nephrol Transplant, 2014. 7(2): p. 91-6.

19. Makhlough, A., et al., Relationship between serum intact parathyroid hormone and pruritus in hemodialysis patients. Iran J Kidney Dis, 2013. 7(1): p. 42-6.

20. Min, J.W., et al., Comparison of uremic pruritus between patients undergoing hemodialysis and peritoneal dialysis. Kidney Res Clin Pract, 2016. 35(2): p. 107-13.

21. Ramakrishnan, K., et al., Clinical characteristics and outcomes of end-stage renal disease patients with selfreported pruritus symptoms. International journal of nephrology and renovascular disease, 2013. 7: p. 1-12.

22. Simonsen, E., et al., Treatment of Uremic Pruritus: $A$ Systematic Review. Am J Kidney Dis, 2017. 70(5): p. 638655.

23. Arzhan, S., M.E. Roumelioti, and M.L. Unruh, Itch and Ache on Dialysis: New Approaches to Manage Uremic Pruritus and Restless Legs. Blood Purif, 2020. 49(1-2): p. 222-227.

24. Mettang, T. and A.E. Kremer, Uremic pruritus. Kidney Int, 2015. 87(4): p. 685-91.

25. Malekmakan, L., et al., Treatments of uremic pruritus: $A$ systematic review. Dermatol Ther, 2018. 31(5): p. e12683.

26. Deshmukh, S.P., et al., Clinicoepidemiological study of skin manifestations in patients of chronic renal failure on hemodialysis. Indian dermatology online journal, 2013. 4(1): p. 18-21.

27. Khanna, D., A. Singal, and O.P. Kalra, Comparison of cutaneous manifestations in chronic kidney disease with or without dialysis. Postgrad Med J, 2010. 86(1021): p. 641-7.

28. Attia, E.A., S.I. Hassan, and N.M. Youssef, Cutaneous disorders in uremic patients on hemodialysis: an Egyptian case-controlled study. Int J Dermatol, 2010. 49(9): p. 102430.

29. Dahbi, N., et al., [Cutaneous manifestations in hemodialysis patients]. Nephrol Ther, 2014. 10(2): p. 101-5.

30. Kolla, P.K., et al., Cutaneous manifestations in patients with chronic kidney disease on maintenance hemodialysis. ISRN Dermatol, 2012. 2012: p. 679619

31. Morton, C.A., et al., Pruritus and skin hydration during dialysis. Nephrol Dial Transplant, 1996. 11(10): p. 2031-6.

32. Lupi, O., et al., Manifestações cutâneas na doença renal terminal \%J Anais Brasileiros de Dermatologia. 2011. 86: p. 319-326.

33. Dalgaard, L.S., et al., Risk and Prognosis of Bacteremia and Fungemia Among Peritoneal Dialysis Patients: A PopulationBased Cohort Study. Perit Dial Int, 2016. 36(6): p. 647-654.

34. Munshi, R., et al., Fungal peritonitis in the Standardizing Care to Improve Outcomes in Pediatric End Stage Renal Disease (SCOPE) Collaborative. Pediatr Nephrol, 2018. 33(5): p. 873-880.

35. Onelmis, $\mathrm{H}_{\text {., }}$ et al., Cutaneous changes in patients with chronic renal failure on hemodialysis. Cutan Ocul Toxicol, 2012. 31(4): p. 286-91.
36. Udayakumar, P., et al., Cutaneous manifestations in patients with chronic renal failure on hemodialysis. Indian J Dermatol Venereol Leprol, 2006. 72(2): p. 119-25.

37. Abdelaziz, A.M., et al., Nail changes in kidney transplant recipients. Nephrol Dial Transplant, 2010. 25(1): p. 274-7.

38. Lamb, F.M., et al., Frequency of onychomycoses in chronic renal failure patients undergoing hemodialysis in Porto Alegre, Brazil. Acta Dermatovenerol Croat, 2013. 21(1): p. 19-23.

39. Markova, A., et al., Diagnosis of common dermopathies in dialysis patients: a review and update. Semin Dial, 2012. 25(4): p. 408-18.

40. Lupi, O., et al., Cutaneous manifestations in end-stage renal disease. An Bras Dermatol, 2011. 86(2): p. 319-26.

41. Mohamadi MM, Goodarzi A, Aryannejad A, Fattahi N, Alizadeh-Khoei M, Miri S, et al . Geriatric challenges in the new coronavirus disease-19 (COVID-19) pandemic: A systematic review. Med J Islam Repub Iran. 2020; 34 (1):841-848. Doi: https://doi.org/10.47176/mjiri.34.123.

42. Seirafianpour F, Mozafarpoor S, Fattahi N, SadeghzadehBazargan A, Hanifiha M, Goodarzi A. Treatment of COVID19 with pentoxifylline: Could it be a potential adjuvant therapy? DermatolTher. 2020 May 30;33(4):e13733. doi: 10.1111/dth.13733.

43. Atefi NS, Behrangi E, Mozafarpoor S, Seirafianpour F, Peighambari S, Goodarzi A. N-acetylcysteine and coronavirus disease 2019: May it work as a beneficial preventive and adjuvant therapy? A comprehensive review study.J Res Med Sci 2020;25:109. doi: 10.4103/jrms.JRMS_777_20.

44. Seirafianpour F, Sodagar S, Pour Mohammad A, Panahi P, Mozafarpoor S, Almasi S, Goodarzi A. Cutaneous manifestations and considerations in COVID-19 pandemic: A systematic review. Dermatol Ther. 2020 Jul 8;33(6):e13986. doi: $10.1111 /$ dth.13986.

45. Nobari NN, Goodarzi A. Patients with specific skin disorders who are affected by COVID-19: What do experiences say about management strategies? A systematic review.DermatolTher. 2020 Jun 18;33(6):e13867. doi: 10.1111/dth.13867.

46. Sadeghzadeh-Bazargan A, Behrangi E, Goodarzi A. Systemic retinoids in the COVID-19 era - are they helpful, safe, or harmful? a comprehensive systematized review study. Iran J Dermatol.2020; 23 (Supp.1): S9-12. DOI: 10.22034/ijd.2020.114847.

47. Sadeghzadeh-Bazargan A, Behrangi E, Goodarzi A. Cytokine storm and probable role of immunoregulatorydrugs in COVID-19: A comprehensive review study. Iran J Dermatol.2020; 23 (Supp.1): S13-18. DOI: 10.22034/ijd.2020.114848.

48. NajarNobari N, Seirafianpour F, Mashayekhi F,Goodarzi A. A systematic review on treatment-related mucocutaneous reactions in COVID-19patients.DermatolTher. 2020; 34(1): e14662.doi: 10.1111/dth.14662. PMID: 33301232.

49. Mohamadi M, Fattahi N, Goodarzi A, Alizadeh-Khoei M, MiriSh, Hekmat H, Bodaghabadi M, Nikkhah F. A Comprehensive Review on COVID-19 Infection and Comorbidities of Various Organs.Acta Med Iranic. 2021;59(1):4-14. https://doi.org/10.18502/acta.v59i1.5396.

50. NajarNobari N, Montazer F, SeirafianpourF, Nikkhah F, Aryanian Z, Goodarzi, A. Histopathologic Changes and Cellular Events of Organs Systems in COVID-19. J Cell MolAnesth. 2021;6(1):81-88. https://doi.org/10.22037/jcma.v6i1.32528

51. Kooranifar S, Sadeghipour A, Riahi T, Goodarzi A, Tabrizi S, Davoody N. Histopathologic survey on lung necropsy specimens of 15 patients who died from COVID-19: A large study from Iran with a high rate of anthracosis. Med J Islam Repub Iran. 2021(17 May);35:63. doi.org/10.47176/mjiri.35.x 
52. NajarNobariN, SeirafianpourF, DodangehM, SadeghzadehBazargan A, Behrangi E, MozafarpoorS, GoodarziA . systematic review of the histopathologic survey on skin biopsies in patients with Corona Virus Disease 2019 (COVID-19) who developed virus or drug-related mucocutaneous manifestations. Exp Dermatol. 2021 May $11 ; 10.1111 /$ exd.14384. doi: $10.1111 /$ exd.14384.

53. Sadeghzadeh-

Bazargan A, RezaiM, NajarNobariN, MozafarpoorS, Goodar ziA. Skin manifestations as potential symptoms of diffuse vascular injury in critical COVID-19 patients. J Cutan Pathol. $2021 \quad$ May 12;10.1111/cup.14059. doi: 10.1111/cup.14059.

54. Kalantari S, Sadeghzadeh-Bazargan A, Ebrahimi S, Yassin Z, Faiz SHR, Kabir A, Baghestani A, Mashayekhi F, Bokharaei-Salim F, Goodarzi A. The effect of influenza vaccine on severity of COVID-19 infection: An original study from Iran.Med J Islam Repub Iran. 2021(7 Sep);35:114. https://doi.org/10.47176/mjiri.35.114.

55. Riahi T, Sadeghzadeh-Bazargan A, Shokri S, Ahmadvand D, Hassanlouei B, BaghestaniA, Khazaeian A, SeifiGharabaghloo F, Hassanzadeh M, Goodarzi A. The effect of opium on severity of COVID-19 infection:An original study from Iran.Med J Islam Repub Iran. 2021(8 Sep);35:115.https://doi.org/10.47176/mjiri.35.115.

56. Tajalli F, Mirahmadi SM, Mozafarpoor S, Goodarzi A, Nasiri Partovi M, Lakestani D. Mucocutaneous manifestations of patients with chronic kidney disease under hemodialysis: A cross-sectional study of 49 patients. Dermatologic Therapy. 2021 Jun 2:e15015. 